\title{
Claudio Sánchez-Albornoz y la preocupación por el método o cómo hacer historia medieval desde América Latina
}

\author{
Claudio Sánchez-Albornoz e a preocupação por o método ou como fazer a história \\ medieval da América Latina \\ The importance of the method in Claudio Sánchez-Albornoz or how to do Medieval \\ History from Latin America
}

\author{
Martin Federico Rios Saloma* \\ Universidade Autônoma do México (UNAM), Cidade do México, México
}

\begin{abstract}
RESUMEN: En el presente trabajo se estudian las contribuciones del medievalista español Claudio Sánchez-Albornoz al desarrollo de los estudios medievales en América Latina y la manera en que a través de una práctica cotidiana superó los problemas de orden metodológico a los que se enfrentó durante sus primeros años de exilio en Argentina. En este sentido, el trabajo pone de relieve la importancia que tuvieron sus años de formación en España, sus vínculos con el medievalismo europeo de la época y el buen conocimiento de los fondos documentales españoles como pilares para sustentar su labor docente e investigadora en el exilio.
\end{abstract}

PALABRAS CLAVE: España. Historia. Historiografía. Edad media. Sánchez-Albornoz.

RESUMO: No presente trabalho estudamos as contribuições do medievalista espanhol Claudio Sánchez- Albornoz para o desenvolvimento dos estudos medievais na América Latina e a maneira pela qual, através da prática diária, ele superou os problemas metodológicos que enfrentou durante seus primeiros anos de exilio na Argentina. Nesse sentido, o trabalho destaca a importância de seus anos de formação na Espanha, suas ligações com o medievalismo europeu da época e o bom conhecimento das coleções documentais espanholas como pilar para apoiar seu trabalho de ensino e pesquisa no exillio argentino.

PALAVRAS-CHAVE: Espanha. História. Historiografia. Idade média. Sánchez-Albornoz.

\footnotetext{
* Professor e pesquisador do Instituto de Investigações Históricas da Universidade Autônoma do México (UNAM), Cidade do México, México. Doutor em História pela Universidade Complutense de Madrid. Essa pesquisa foi financiada pelo Programa de Apoyo a la Superación Académica (PASPA), Dirección General de Asuntos del Personal Académico (DGAPA), UNAM. E-mail: riosmartin76@gmail.com
} 
ABSTRACT: This paper explore the contributions of the Spanish medievalist Claudio Sánchez-Albornoz to the development of medieval studies in Latin America and the way in which, through daily practice, he overcame the methodological problems he faced during his early years of exile in Argentina. In this sense, the work highlights the importance of his formative years in Spain, his links with the European medievalism of his period and the good knowledge of the Spanish documentary collections as pillars with which to support his teaching and research work in his Argentinian exile.

KEYWORDS: Spain. History. Historiography. Middle ages. Sánchez-Albornoz.

\section{Claudio Sánchez-Albornoz: un medievalista en América Latina}

Claudio Sánchez-Albornoz (1893-1984) fue uno de los medievalistas españoles más importantes del siglo XX y contribuyó significativamente a renovar la disciplina histórica en general y los estudios medievales en particular en su país natal, al menos durante la primera mitad de la centuria pasada. ${ }^{1}$ Tal renovación se materializó en la búsqueda constante del diálogo con los medievalistas más importantes de su época como Marc Bloch, Louis Halphen, Louis Ganshof o Alphons Dopsch, por mencionar sólo a los más destacados, así como en el ejercicio continuado de la crítica documental y la erudición de raigambre alemana.

Esta contribución ha sido ponderada positivamente por diversos estudiosos de la obra de Sánchez-Albornoz a ambos lados del Atlántico (PASTOR, 1993, p. 14-15; GONÁLEZDE FAUVE, 2001-2002, p. 209-210), aunque no siempre con todo su significado. Así, por ejemplo, en 1994 Carlos Astarita señalaba en un breve texto editado para conmemorar el centenario del natalicio de Sánchez-Albornoz a propósito de la erudición del historiador madrileño que "la metodología positivista se encuentra presente como una constante en toda [su] obra” y remarcaba su preocupación por los referentes documentales que el medievalista español empleaba "como inexcusables celadores de objetividad sobre los que edificaba una causalidad progresivamente pautada” (ASTARITA, 1994, p. 7). Aunque el medievalista argentino valoraba a continuación los aportes del método, no remarcaba ni ponderaba suficientemente lo que estaba detrás de esas profusas y eruditas notas en las que se alternaban referencias documentales y bibliográficas en latín, alemán, español, francés y portugués - con la notable ausencia del inglés: la genuina preocupación de Sánchez-Albornoz y su generación, representada por el método histórico, un método que hiciera de la Historia una auténtica ciencia social y que, al mismo tiempo, liberara a la disciplina de los límites a los que la había constreñido el positivismo de finales del siglo XIX.

Como es sabido, Sánchez-Albornoz se asentó en Argentina como consecuencia del alzamiento militar en contra del gobierno de la Segunda República en el que había desempeñado importantes cargos como Diputado por la provincia de Ávila, consejero de instrucción pública, Rector de la Universidad Central, Ministro de Estado y embajador en Portugal (CABEZA SÁNCHEZALBORNOZ, 1992). Su paso por la Universidad de Mendoza entre diciembre de 1940 y julio de 1942 y su posterior incorporación a la Universidad de Buenos Aires a partir de esta última fecha, significaron la génesis de una escuela de medievalistas en el país sudamericano, desde la cual el historiador madrileño y su grupo de discípulas argentinas nutrieron y enriquecieron los debates sobre el desarrollo histórico de la península ibérica a lo largo de la alta y la plena Edad Media.

Ciertamente no puede decirse que Sánchez-Albornoz iniciara los estudios sobre la Edad Media en América Latina. En Argentina, por ejemplo, Clemente Ricci, Alberto Freixas o José 
Luis Romero habían iniciado el estudio de este periodo de la historia europea en la capital porteña desde finales de la década de 1920, llegando a adquirir el segundo las colecciones completas de los Monumenta Germaniae Histórica y la Patrología Latina (RÍOS SALOMA, 2018, p. 256). En México, por su parte, Luis Weckmann publicaba su primer trabajo sobre La sociedad feudal en 1944 (WECKMANN, 1944), mientras que en Brasil Eurípides Simoes de Paula defendía su tesis doctoral en la Universidad de Sao Paulo sobre el comercio en el principado de Kiev (1942) (BARROS ALMEIDA, 2008, p. 156) y en Chile Héctor Herrera Cajas inauguraba, a principios de la década de 1950, la enseñanza Historia Antigua y Medieval en la Universidad de Chile y en la Universidad Católica de Valparaíso (ROJAS DONAT, 2015, p. 50). ¿Dónde radica entonces la originalidad del aporte de don Claudio?

Desde nuestra perspectiva, la respuesta consiste, precisamente, en el desarrollo del método de investigación propio del medievalismo y la utilización sistemática de las fuentes escritas. Pero si a lo largo del último tercio del siglo XIX y las primeras tres décadas del siglo XX la pregunta por el método histórico había tenido un valor de primer orden, ésta se resignificaba desde la nueva posición trasatlántica de don Claudio: ¿cómo estudiar la historia de la alta Edad Media hispana desde Buenos Aires, en donde no había documentos de archivo y las fuentes editadas eran pocas? Y mejor aún, ¿cómo garantizar que esa historia estuviera a la altura de la que se realizaba en Viena, París o Roma? La pregunta no era baladí, pues Charles Langlois y Charles Seignobos (1898) habían afirmado categóricamente que la historia sólo podía hacerse con documentos y, aunque Bloch y Febvre combatían asiduamente por ampliar la noción de fuente histórica, lo cierto era que en el ámbito del medievalismo la posibilidad de acceder a la fuente directa - o a su edición erudita - era, y es, la única garantía de cientificidad.

En este trabajo analizaremos en consecuencia la manera en que con su quehacer cotidiano y su preocupación por el método histórico Claudio Sánchez-Albonoz contribuyó significativamente al desarrollo de los estudios medievales en América Latina al introducir las propuestas de aquella generación de medievalistas que pretendió conquistar para la disciplina histórica un lugar propio en el campo de las ciencias sociales. Para ello haremos un breve repaso de sus años de formación y consolidación con el fin de resaltar la forma en que durante ellos se apropió de dicha metodología y analizaremos a continuación la producción de sus primeros años en Argentina tomando como fuente los artículos que el medievalista español publicó en los primeros números de los Cuadernos de Historia de España, revista por él fundada en 1942 como órgano de divulgación de sus actividades científicas en el Instituto de Historia de España de la Universidad de Buenos Aires (RÍOS SALOMA, 2018).

\section{Años de formación y consolidación (1914-1940)}

Se ha repetido numerosas veces que Sánchez-Albornoz fue discípulo de Eduardo de Hinojosa en la Universidad Central de Madrid y que éste le inclinó por la historia institucional (FONT RIUS, 1993-1994). Pero pocas veces se ha dicho que Hinojosa fue uno de los autores que participó en el volumen correspondiente de la Historia de España coordinada por Cánovas del Castillo que pretendía ser la Historia de España escrita con los criterios científicos de la época - rigor, erudición, crítica documental externa e interna - que superara la interpretación romántica de Modesto Lafuente (TOMÁS Y VALIENTE, 1993-1994). En este sentido, Sánchez-Albornoz heredó de 
su maestro una forma de hacer historia considerada científica que se oponía a la elaborada por aficionados, diletantes y profesores de secundaria como Aureliano Fernández Guerra, Eduardo Saavedra ${ }^{2}$ o Ricardo Burguete a los que éste criticaría su falta de método y rigor desde el primero de sus artículos publicados en Cuadernos (SÁNCHEZ-ALBORNOZ, 1944, p. 15, 18, 22).

Sánchez-Albornoz obtuvo su doctorado en 1914 con la tesis intitulada "La potestad real y los señoríos en Asturias, León y Castilla durante los siglos VIII al XIII” en la cual se enfrentó por vez primera con la documentación de archivo (SÁNCHEZ-ALBORNOZ, 1914). Al año siguiente, ingresó al cuerpo Facultativo de Archiveros, Bibliotecarios y Arqueólogos por oposición y trabajó durante tres años en el Archivo Histórico Nacional, lo que le dio la posibilidad de conocer en profundidad la documentación alto medieval custodiada en ese importante repositorio. En 1917 solicitó un permiso ante el Archivo y una pensión de la Junta de Ampliación de Estudios para realizar una estancia de investigación de tres meses en los archivos portugueses. ${ }^{3}$ Producto de dicha estancia fue el trabajo La curia regia portuguesa, con el que en la práctica mostraba nuestro joven historiador que si quería comprenderse cabalmente el pasado medieval de peninsular no debían proyectarse hacia los siglos altomedievales las fronteras políticas constituidas a lo largo de la plena Edad Media (SÁNCHEZ-ALBORNOZ, 1920). Durante todo este tiempo, Sánchez-Albornoz no dejó de asistir asiduamente al Centro de Estudios Históricos en el que Hinojosa desempeñaba su actividad investigadora y en el que, además, se benefició del magisterio de personalidades como Ramón Menéndez Pidal o Manuel Gómez Moreno.

En junio de 1918 Sánchez-Albornoz obtuvo por oposición el cargo de Catedrático de Historia Antigua y Medieval en la Facultad de Filosofía y Letras de Barcelona, pero aunque tomó posesión de ésta administrativamente, no llegó a desplazarse a la ciudad condal, pues en julio del mismo año solicitó su traslado por permuta a la Universidad de Valencia, a la que estuvo adscrito hasta enero de 1919, cuando se incorporó efectivamente a la Universidad de Valladolid y en la que, a lo largo de todo ese año, desempeñó su magisterio. ${ }^{4}$ En enero de 1920 logró su traslado a la Universidad Central de Madrid, donde ocupó la Cáted ra que había dejado vacante al morir su maestro Hinojosa.

La vuelta a Madrid supuso el inicio de un periodo sumamente fecundo para don Claudio. Entre 1921 y 1922, realizó diversos viajes al norte de la península para reunir materiales con los cuales elaborar el estudio con el que concurso al Premio Covadonga, convocado por las Academias Española y de la Historia para conmemorar el aniversario de la batalla. Debido al rigor de su labor y la importante cantidad de materiales inéditos que aportaba, su trabajo intitulado Instituciones sociales y politicas del reino de Asturias, se hizo en 1923 con el ansiado Premio. 5 Al año siguiente, Sánchez-Albornoz y un grupo de discípulos de Hinojosa fundaron el Anuario de Historia del Derecho Español como un órgano especializado de comunicación - en el que Marc Bloch llegó a publicar, incluso, en dos ocasiones (BLOCH, 1926; BLOCH, 1933) - y al año siguiente fue admitido en la Real Academia de la Historia, en la que leyó un discurso intitulado Estampas de la vida en León hace mil años y en el que abordaba aspectos de historia económica, historia social y vida cotidiana (SÁCHEZ-ALBORNOZ, 1926).

Durante el bienio 1927-1928, una beca de la Junta de Ampliación de estudios le permitió participar en los seminarios de Alphons Dopsch en Viena a los que nos hemos referido y perfeccionar el método de trabajo. Al volver a España no sólo fundó el Instituto de Estudios Medievales en el Centro de Estudios Históricos de Madrid (1932), alternando su labor investigadora con la política, sino que, inspirado por la experiencia en el ámbito alemán, desarrolló la idea de elaborar unos Monumenta Hispaniae Historica, proyecto para el cual logró el apoyo del gobierno de la 
República mediante un Decreto por el cual éste concedía el presupuesto necesario (SÁNCHEZALBORNOZ, 1932, p. 504-508) y para el cual había logrado reunir en "su" Instituto "más de veinte mil fotografías de documentos del N. y NO. de España” (SÁNCHEZ-ALBORNOZ, 1944 , p. 410). Desde su exilio argentino apostillaría años después: "Ignoro cuál ha sido la suerte de las veinte mil fotografías que habíamos reunido en el Instituto de Estudios Medievales y en qué estado se halla la publicación de los Monumenta Hispaniae Historica que preparábamos, ni sé si se habrá continuado el mapa 'España en el año mil'” (SÁNCHEZ-ALBORNOZ, 1944c, p. 416). ${ }^{6}$

Durante este tiempo, sus intereses sobre el origen del reino asturiano se habían ampliado y en el centro de su actividad científica se hallaban los debates en torno a los orígenes del feudalismo. El interés por este tema le llevó a organizar en Madrid y Salamanca en 1932 un importante coloquio al que intituló Semana de Historia del Derecho Español a la que asistieron, entre otros, March Bloch, Louis Halphen, Ferdinand Lot, Olivier Martin y Paulo Merea (SÁNCHEZ-ALBORNOZ, 1932b) y a escribir diversos textos para contestar las teorías de Mayer sobre los orígenes del feudalismo (SÁNCHEZ-ALBORNOZ, 1927). Cuando el estallido de la guerra civil le llevó a refugiarse en Burdeos - por cuya Universidad era doctor Honoris Causa - Sánchez-Albornoz continuó trabajando sobre su gran proyecto acerca de Los orígenes del feudalismo y ello es lo que explica que su obra homónima fuese publicada en Mendoza por la Universidad Nacional de Cuyo (SÁNCHEZ-ALBORNOZ, 1942).

De esta suerte y a modo de recapitulación, puede afirmarse que, a diferencia de sus coetáneos latinoamericanos que iniciaban su andadura intelectual en el ámbito del medievalismo en la década de 1940, Sánchez-Albornoz llevaba dos décadas trabajando como medievalista profesional, conocía como nadie en América Latina los archivos españoles y sus problemáticas, dominaba la bibliografía más actualizada sobre sus temas de interés y se había insertado plenamente en los debates europeos de su tiempo manteniendo una importante actividad epistolar con sus principales interlocutores.

\section{El ejercicio del método}

Claudio Sánchez-Albornoz compartía con todos los historiadores de su generación, formados a principios del siglo XX, la idea de que la historia sólo podía hacerse con documentos y eran precisamente éstos los que le faltaban en su exilio argentino. Ello le llevó durante los primeros años a lamentarse una y otra vez sobre la imposibilidad de acceder a las fuentes originales, de haber perdido parte de sus notas en algún punto del camino y de la requisición de su biblioteca personal por parte del régimen durante la guerra civil. Pero nuestro historiador tenía tres enormes ventajas para desarrollar su trabajo en la vertiente americana del Atlántico. En primer lugar, su larga experiencia en el quehacer histórico e historiográfico a la que nos hemos referido. En segundo término, el hecho de que en la capital argentina - que era un importante y estimulante foco intelectual - existían materiales bibliográficos altamente aprovechables y que el azar había querido que en su periplo vital Sánchez Albornoz salvara - a pesar de sus constantes lamentos - no pocos de sus materiales, de tal suerte que en la "Advertencia" que antecede el número 1 de los Cuadernos, el abulense señalaba que "por fortuna” [había] logrado salvar muchas de mis fotocopias y de mis notas" y añadía que "[había] hallado en Buenos Aires muchos textos indispensables para nuestros trabajos” (SÁNCHEZ-ALBORNOZ, 1944, p. 8). Finalmente, hecho no menor, don Claudio poseía una memoria portentosa y no son infrecuentes las notas en las que advertía que escribía de memoria. Así, por ejemplo, en un artículo sobre el senatus visigodo escribe: 
No estoy seguro - dice en algún punto cualquiera a modo de ejemplo - de las últimas citas de Stein, porque mis notas sobre todos estos trabajos, como las de la mayoría de las obras que vengo citando en mis libros argentinos, acerca de la historia de las instituciones, proceden de mis lecturas y apuntes de Burdeos y he perdido por desgracia los procedentes de Stein” (SÁNCHEZ-ALBORNOZ, 1946, p. 65).

Historiador riguroso y profesional, Sánchez-Albornoz no dejó de reflexionar, por otra parte, sobre el método histórico, los alcances y límites de la disciplina y el sentido de la historia. Sin embargo, pensaba, como muchos historiadores de su tiempo, que la reflexión sobre la Historia era más propia de filósofos que de historiadores y fue por ello que prefirió exponer sus ideas sobre la historia en una serie de artículos periodísticos publicados en el diario Los Andes a lo largo de 1943 que en las monografías que publicó en aquellos años. ${ }^{7}$ Sin embargo, sus ideas sobre el método histórico se reflejarían en los Cuadernos de Historia de España de dos maneras: por una parte, a través de la propia práctica de una rigurosa metodología que se mantuvo invariable a lo largo de los años; por la otra, a través de una serie de comentarios y reflexiones sobre el uso de las fuentes y la objetividad histórica deslizados, en la mayoría de los casos, en la crítica a la metodología o a las interpretaciones de los historiadores con los que debatía.

Aunque hoy parezca una obviedad, frente a la forma de escribir de aficionados, diletantes e ideólogos del régimen franquista, la metodología desarrollada por Sánchez-Albornoz siguió siempre este mismo esquema: a) presentación del problema; b) análisis riguroso y exhaustivo de los autores que desde el siglo XIX - y a veces desde el siglo XVIII - habían abordado la cuestión a estudiar, abarcando la producción española, portuguesa, alemana e italiana; c) crítica de fuentes documentales - incluyendo la crítica a las ediciones modernas o contemporáneas de las fuentes, lo que se traducía en muchos casos en un diálogo erudito que atraviesa los siglos -; d) la confrontación exhaustiva de las fuentes archivísticas, cronísticas - latinas y árabes -, epigráficas y arqueológicas, para lo que hacía falta no sólo el conocimiento de los idiomas respectivos - que se asumía como natural -, sino de las herramientas y métodos propios de la filología; e) la exposición de sus propios argumentos y f) la presentación de sus propias conclusiones. En este sentido, puede decirse que Sánchez-Albornoz, que se consideraba así mismo fundador del medievalismo en el mundo latinoamericano, enseñaba en la práctica cómo procedía el medievalista y cuáles eran las fuentes a las que debía acudir.

De todos estos momentos de la praxis historiográfica quisiera detenerme en el que me parece que Sánchez-Albornoz realizó una de las mayores aportaciones en el momento en el que comenzaron a publicarse los Cuadernos de Historia de España: la crítica y la confrontación constante de las fuentes, es decir, la práctica permanente del contraste como método y como vehículo privilegiado de acceso a la verdad. Ello suponía, necesariamente, que el historiador debía librarse de sus prejuicios y no leer los documentos a partir de sus ideas pre-concebidas, sino construir una interpretación a partir de las propias fuentes. Cierto es que el propio don Claudio muchas veces cometió el mismo grave error que criticó en autores tan destacados como Simonet ${ }^{8}$ o Saavedra y que los marcos nacionalistas propios del siglo XIX en los que se había formado moldearon su visión de la historia antigua y medieval de España, pero los Cuadernos son testigo de la permanente búsqueda de la verdad, del ejercicio constante de la honestidad intelectual, de la aspiración por comprender a los hombres del pasado y de un permanente estado de alerta para evitar la mayor de las faltas que puede cometer el historiador: el anacronismo. Unas líneas marginales, escritas a 
pie de página, reflejan con sencillez e intensidad estas legítimas aspiraciones del historiador en el exilio y de la disciplina que practicaba:

Simonet - afirma Sánchez-Albornoz - escribe con saña contra los musulmanes. Los problemas políticos de su época perturbaban la serenidad de su juicio y le mueven a emplear palabras y conceptos de sus días. Pelayo es para él, por ejemplo, el jefe del partido católico. ¡Cómo resuena en ese calificativo el eco de las polémicas de la Restauración y de la Regencia! Es difícil al historiador librarse del mundo de ideas y términos que danzan en torno de su mente; pero será poco cuanto haga por conseguir adentrarse en el de los hombres cuya vida trata de captar. (SÁNCHEZ-ALBORNOZ, 1944a, p. 20, nota 35).

La crítica de la fuente era, pues, la piedra angular sobre la cual se apoyan las grandes construcciones históricas: "Hemos pecado todos contra los testimonios precisos de las fuentes" - reconoce don Claudio en su madurez (SÁNCHEZ-ALBORNOZ, 1944a, p. 33) -, para añadir a continuación:

Se olvidan con frecuencia los peligros que suscita en el camino de los historiadores la falta de una crítica severa de las fuentes, la falta de una discriminación científica de sus valores y de su autoridad. Y la moda cambiante de colocar, a las veces en el primer plano de la atención de los estudiosos, textos que no pueden competir en crédito con otros menos afortunados. La ausencia de un estudio detenido de la historiografía disponible para conocer la historia hispano-musulmana, el desdén sentido por muchos eruditos contemporáneos hacia el problema del análisis de las fuentes y el empleo de éstas a capricho, ha restado solidez a diferentes obras construidas con gran allegamiento de materiales sin cernir (SÁNCHEZ-ALBORNOZ, 1944a, p. 32).

Y señalaba que ello había ocurrido en particular con "la crónica de la invasión de España por los árabes y la de los orígenes de la Reconquista” (SÁNCHEZ-ALBORNOZ, 1944a, p. 32), hecho sobre el cual la historiografía desde el mismo siglo VIII había hecho correr ríos de tinta y toneladas de papel, generado una erudita polémica en la que habían participado las plumas más autorizadas de los últimos cuatros siglos. No entraremos aquí en el debate sobre las "causas y consecuencias" - para decirlo con el lenguaje de don Claudio - de la invasión islámica. Quedémonos con el hecho esencial: en un tema tan importante y determinante para la historia de España como era la conquista musulmana de la península ibérica, el hecho de que las fuentes no se hubiesen criticado y empleado correctamente hacía, según el parecer de Sánchez-Albornoz, que todo lo que se había escrito hasta entonces careciese de la solidez y el rigor necesario para ser considerado como conocimiento histórico verdadero. Sánchez-Albornoz, él, el alumno dilecto de Hinojosa, discípulo de Dopsch y amigo de Bloch, sería el encargado de escribir, por fin, la auténtica historia de la pérdida de España y de los Orígenes de la Nación española y "rectificar", entre tantas cosas, "la fecha de la batalla de Covadonga" (SÁNCHEZ-ALBORNOZ, 1944a, p. 76). Sin embargo, conocedor también de sus límites y, sobre todo, consciente de la carencia de fuentes, se vería obligado a ser prudente y a no dar nunca una conclusión por definitiva':

Son caducos y perecederos los estudios históricos - afirma don Claudio. El hallazgo de nuevas fuentes y una más despaciosa o penetrante exégesis de las conocidas va renovando las construcciones, al parecer mejor fundadas, de las más sólidas y eruditas monografías. Ninguna página de la Historia escapa a tal envejecimiento y a tal crítica; y quienes sentimos con pasión 
el acicate de la posesión de la verdad, no podemos sino felicitarnos de tales avances, aunque ellos se realicen a costa de nuestras propias investigaciones" (SÁNCHEZ-ALBORNOZ, 1946, p. 129).

Ahora bien: ¿cómo debe realizarse la crítica de fuentes según el medievalista madrileño? Ante todo, había que deshacerse de los prejuicios y evitar el extremo contrario, es decir, el hipercriticismo, que no se cansó de acusar y señalar en Barrau-Dihigo, por ejemplo ${ }^{10}$. Segundo, era necesario disponer de una gran cantidad de documentos y, de preferencia, de los documentos originales. Sánchez-Albornoz haría hincapié, una y otra vez, en que la legitimidad de su trabajo científico, incluso en ciudades tan alejadas de los focos del medievalismo europeo como Mendoza o Buenos Aires, estaba sustentada en utilizar materiales que o bien tenía consigo reproducidos en fotocopias o fotografías, o bien había visto en su soporte original y había transcrito pacientemente durante sus jornadas de trabajo en los archivos catedralicios del noroeste peninsular, en los fondos portugueses o en los repositorios madrileños. ${ }^{11}$ En tercer lugar, "era preciso comenzar por estudiar científicamente las fuentes históricas; era preciso discriminar su valor y su autoridad” (SÁNCHEZ-ALBORNOZ, $1944 a$, p. 75) ayudándose del método filológico y poniendo en práctica las herramientas que en el siglo XVII había ideado el viejo Mabillon, las cuales no eran otras que "los buenos principios de la crítica histórica" (SÁNCHEZ-ALBORNOZ, 1945, p. 57), es decir: el estudio de la datación de las actas - es decir, de la cronología -, la descripción de las invocaciones, el estudio de las fórmulas jurídicas, el análisis nominal de los notarios firmanes, la confrontación con diversos grupos documentales y, en fin, la utilización de los argumentos históricos. Finalmente, y por lo que correspondía en especial a la historia medieval de la península ibérica, era prescriptivo realizar "el examen científico de las crónicas árabes y cristianas” (SÁNCHEZ-ALBORNOZ, 1944a, p. 75) con el fin de confrontar los textos.

Este último ejercicio intelectual, la confrontación de textos latinos y árabes era también una novedad, pues debido a la propia trayectoria de la escuela de estudios árabes e islámicos española inaugurada por Condé y continuada por Pascual de Gayangos, Francisco Codera y Eduardo Saavedra a lo largo del siglo XIX, así como por los propios derroteros del medievalismo, los puntos de contacto eran pocos y los estudiosos dedicados a los reinos hispano-cristianos por lo general desconocían el árabe y no siempre tomaban en cuenta para sus trabajos las fuentes musulmanas. Es por ello que don Claudio, si bien no podía leer en árabe, se servía de las distintas traducciones que estaban a su alcance como las de Codera, Gayangos, Dozy, Ribera y Levi Provençal, abordaba los problemas historiográficos que le presentaban las fuentes árabes (SÁNCHEZ-ALBORNOZ, 1944c) y llegó a editar, incluso, una colección de fuentes árabes traducidos al castellano (SÁNCHEZ-ALBORNOZ, 1946d). Para Sánchez-Albornoz, la única posibilidad de realizar una historia científica de la península ibérica consistía en poder contrastar las fuentes árabes con las latinas y ofrecer así una visión de conjunto.

En el marco intelectual que se desenvolvía Sánchez-Albornoz, se consideraba que una vez depuradas las crónicas de las noticias falsas, las interpolaciones y las imprecisiones, corregidos los nombres y hecha la lectura correcta de las fechas, se podía establecer la verdad histórica y reconstruir los hechos tal y como habían acontecido; no es ocioso recordar que aún faltaban tres décadas para la emergencia del giro lingüístico y el cuestionamiento de tales postulados. En cualquier caso, nuestro historiador afirmaba "tener a la vista” (SÁNCHEZ-ALBORNOZ, 1944a, p. 48), entre otros, la historia de Al-Maqqari sobre los “Omeyas españoles” publicada por Pascual Gayangos en 
su The bistory of the Mohammedan Dynasties in Spain, publicada entre 1840 y 1843 (SÁNCHEZ-ALBORNOZ, 1944a, p. 48, nota 151).

"No me detienen, sino que me entusiasman las dificultades", solía decir Sánchez-Albornoz de sí mismo (SÁNCHEZ-ALBRNOZ, 1944a, p. 75). Subsanar la falta de documentos con los cuales estudiar la historia de la península ibérica sería, por tanto, uno de los principales objetivos de Sánchez-Albornoz. Orgulloso de haber sido el primer laico en acceder a los fondos documentales de la sede ovetense (SÁNCHEZ-ALBORNOZ, 1944b, p. 308), ${ }^{12}$ nuestro historiador afirmaba que había fotografiado numerosos documentos en sus distintas visitas y que tenía "las fotografías en Buenos Aires", fotografías que le servirían para publicar "en estos Cuadernos [...] algunos de los diplomas ovetenses" (SÁNCHEZ-ALBORNOZ, 1944b, p. 308, nota 62). Sin embargo, su prurito científico le llevaba a reconocer, al mismo tiempo que no disponía de todo el material que necesitaba: "de varios documentos - sostiene - no poseo en Buenos Aires fotografías, y he de conformarme, por tanto, con reproducir las viejas copias que hice, hace muchos años, de sus originales”. (SÁNCHEZ-ALBORNOZ, 1944b, p. 351).

Fue precisamente con base en esas fotografías de documentos que Sánchez-Albornoz publicó en el primer número de los Cuadernos de Historia de España una colección de documentos medievales peninsulares que sería, hasta donde me lo permiten afirmar mis investigaciones, una de las primeras realizadas en Latinoamérica. En este sentido, el primer número de los Cuadernos representa la piedra fundacional del medievalismo argentino en su vertiente albornociana, que bebía a la postre de la escuela crítica alemana y francesa que había encontrado en la Introducción a los estudios históricos de Langlois y Seignobos su concreción más acabada, de tal guisa que quiso don Claudio que los Cuadernos fuesen el manantial del cual pudiesen beber los interesados en el pasado medieval de España. Para ello ideó una sección documental como la que en su día había sido concebida para el Anuario de Historia del Derecho español en la que a lo largo de los años se editaron numerosas fuentes archivísticas y cronísticas - particularmente traducciones del árabe al castellano - con las cuales cultivar la historia y de las que Sánchez-Albornoz sabría extraer en su exilio argentino numerosas y valiosas informaciones.

Inspirado por la creación, en 1943, del Instituto Antonio de Vasconcelos en Coimbra a iniciativa de sus amigos Paulo Merea y Souza Soares, Sánchez-Albornoz se sentía "autorizado a esperar que el día de la paz podremos reunir en Buenos Aires la misma colección de fotocopias que hoy guardan ya en Coimbra y en Madrid, y que podremos trabajar aquí con la misma holgura de elementos que en España y Portugal” (SÁNCHEZ-ALBORNOZ, 1944e, p. 416). Y añadía entusiasmado:

Si cuando la normalidad de las comunicaciones se restablezca en el mundo y cuando puedan traerse fotocopias de los manuscritos arábigos del Escorial o de Madrid, de Europa o de África, hay ya en el Plata un grupo de orientalistas, la investigación argentina podrá incorporar a la múltiple serie de sus actividades una más y de gran prestigio en el mundo científico (SÁNCHEZ-ALBORNOZ, 1944e, p. 419).

La historia quiso que Sánchez-Albornoz no volviera a España de forma definitiva y, por lo tanto, ese deseo de trabajar con el centro que dirigían sus amigos portugueses no pudo materializarse. Sin embargo, el medievalista abulense hizo todo lo que estuvo de su parte - burlando la censura del régimen y con la colaboración de muchos antiguos alumnos y amigos que vivían en 
España - para dotar a su Instituto de los materiales necesarios para impulsar la historia medieval: intercambió sus Cuadernos con las revistas científicas que por entonces se editaban, pidió la compra de materiales a la Universidad, solicitó a sus corresponsales españoles que le hiciesen llegar transcripciones de documentos o ediciones de fuentes documentales y cronísticas e integró, a la postre, una magnífica biblioteca personal de la que se nutrieron - según el testimonio de Reyna Pastor - sus discípulos argentinos (PASTOR, 1993, p. 16).

Hoy en día en que el internet y el desarrollo de las nuevas tecnologías han facilitado a los estudiosos latinoamericanos el acceso a las fuentes digitalizadas y en el que los viajes trasatlánticos se han hecho más frecuentes de lo que lo fueron a mediados del siglo XX los afanes de don Claudio parecen quedar muy atrás. Pero ello no debe ser un impedimento para reconocer su valioso aporte metodológico a la disciplina histórica y al desarrollo del medievalismo en nuestra región, por más que estemos obligados también a reconocer otras vías de desarrollo. De esta suerte, frente a los múltiples cuestionamientos que se hicieron durante las décadas de 1970 y 1980 a las propuestas interpretativas de don Claudio, hoy podemos afirmar que de su larga trayectoria queda algo fundamental: el método. Como medievalistas estamos llamados a no olvidar nunca que las fuentes son indispensables para nuestro quehacer cotidiano y, por lo tanto, estamos llamados a adquirir y enseñar las herramientas propias de la erudición histórica y a no rehuir las exigencias de nuestra especialización.

\section{Conclusiones}

Tras este breve repaso que hemos realizado, me parece que pueden ofrecerse distintas conclusiones. La primera de todas ellas, es que Claudio Sánchez-Albornoz no fue el único estudioso en América Latina interesado en desarrollar los estudios medievales sino que, antes bien, compartía esta inquietud con otras personalidades que si bien eran más jóvenes o tenían menos experiencia, buscaban hacerlo con el mismo rigor y seriedad que en Europa. En este sentido, Claudio Sánchez-Albornoz debe ser considerado, más que un fundador, como el estudioso que supo nutrir y apuntalar con su experiencia y su enorme bagaje intelectual el desarrollo del medievalismo latinoamericano, particularmente el que se centraba en el estudio de la península ibérica.

En segundo lugar, me parece necesario reconsiderar la posición historiográfica de Sánchez-Albornoz y su figura en la historia del medievalismo español. Ciertamente los textos que éste publicó a partir de la segunda mitad de la década de 1960 en España pueden considerarse anquilosados o desactualizados si se les compara con las propuestas de un García de Cortázar o un Ladero Quesada o un George Duby, pero no debe de perderse de vista que entre las décadas de 1920 y 1960 y para la época en la que fueron escritos los textos albornocianos no sólo representaron la vanguardia en el ejercicio del método histórico y la crítica documental, sino que muestran la voluntad de Sánchez-Albornoz por contribuir con su quehacer cotidiano a la renovación de la disciplina histórica y a la construcción de su legitimidad como disciplina propia en el ámbito de las ciencias sociales. En este mismo sentido, puede afirmarse que la "guerra de España” y el exilio de nuestro historiador supusieron una abrupta interrupción de aquel proyecto científico, pero no la desaparición de un espíritu crítico sino que, antes bien, a los opúsculos y panegíricos del régimen dictatorial que se hacían pasar por historias - libros de doctrina en realidad - y pretendían manipular el pasado para legitimar al régimen dictatorial, Sánchez-Albornoz opuso el rigor de la erudición histórica. 
Como tercera conclusión puede señalarse que no sólo preocupaban a Sánchez-Albornoz los mismos problemas que a Marc Bloch, con quien le unió una amistad que fue truncada por la guerra, sino que, como él, mostró un interés de primer orden por trascender el ámbito erudito y de convertir a la historia en una disciplina útil que sirviera a los hombres para comprender su presente mediante el estudio del pasado. De ahí que a lo largo de las muchas páginas y los cientos de notas eruditas, de la exhaustiva crítica a las fuentes y de los debates con sus colegas, se mantuviera una constante: la de explicar el ser de España a partir de dos hechos fundamentales, la conquista islámica y el inicio de la Reconquista y que todos sus artículos estuviesen dedicados, de una u otra forma, a arrojar luz sobre la manera en que la primera transformó las estructuras tardo-antiguas de "España” y cómo la segunda contribuyó a fortalecer y definir lo que nuestro autor llamó en su día "la contextura vital hispánica”.

Para el estudioso de hoy es evidente la contradicción entre una historia científica vinculada a las corrientes historicistas marcadas por la idea del cambio y la transformación de las sociedades en el tiempo y unas posturas esencialistas vinculadas a la historia nacional vigente en el siglo XIX y hasta el fin de la segunda guerra mundial. Sánchez-Albornoz, que vivió en medio de esos tiempos convulsos y en medio de esa tensión historiográfica no fue consciente de ello y si lo fue, no pudo abstraerse de sus propios prejuicios y fue vencido por su amor a España y por el peso de unas interpretaciones que se mantuvieron vigentes hasta finales del siglo XX. En cualquier caso, debe señalarse que de esa tensión surgieron páginas brillantes y que esos esencialismos no deben opacar el auténtico mérito de Sánchez-Albornoz: ejercer el oficio de historiador con el máximo rigor metodológico posible alejado de los archivos españoles y de los centros de producción del medievalismo de aquella época, desarrollar la crítica histórica hasta sus últimas consecuencias y mostrar su compromiso irrenunciable con la verdad y con la honestidad intelectual.

\section{Referencias}

ASTARITA, C. A cien años del nacimiento de Claudio Sánchez Albornoz. Anales de Historia Antigua y Medieval, n. 27, p. 5-10, 1994

BARRAU-DIHIGO, L. Recherches sur I'histoire polititique du royaume asturien (718-910). Revue Hispanique, n. 52, p. 1-352, 1921.

BARROS ALMEIDA, N. La formation des médiévistes dans le Brésil contemporain: bilans et perspectives. Bulletin du Centre d'Études Médiévales d'Auxerre, n. 12, p. 145-159. 2008.

BLOCH, M. La organización de los dominios reales carolingios y las teorías de Dopsch. Anuario de Historia del Derecho Español, n. 3, p. 89-119, 1926.

BLOCH, M. Liberté et servitude personnelles au Moyen Âge, particulièrement en France. Contribution à une étude des classes. Anuario de Historia del Derecho Español, n. 10, p. 19-115, 1933.

CABEZA SÁNCHEZ-ALBORNOZ, S. Semblanza histórico política de Claudio Sánchez-Albornoz. León: Fundación Universitaria Española, Diputación Provincial de León, 1992.

FONT RIUS, J. M. Sánchez-Albornoz. Medievalista institucional. Anuario de Historia del Derecho Español, p. 63-64, 1099-1122, 1993-1994.

GONZÁLEZ DE FAUVE, M. E. Don Claudio Sánchez Albornoz y el Instituto de Historia de España de Buenos Aires. Cuadernos de Historia de España, n. 72, p. 207-211, 2001-2002.

LANGLOIS, C.; SEIGNOBOS, V. Introduction aux études historiques. París: La Pleyade, 1898.

PASTOR DE TOGNERI, R. Claudio Sánchez-Albornoz, historiador, maestro y militante. In: PASTOR DE TOGNERI, R. et al. Sánchez-Albornoz a debate: homenaje de la Universidad de Valladolid con motivo de su centenario. Valladolid: Universidad de Valladolid, 1993. p. 9-19. 
RÍOS SALOMA, M. De Europa a América. Claudio Sánchez-Albornoz y la fundación de los Cuadernos de Historia de España. Medievalismo: Boletín de la Sociedad Española de Estudios Medievales, n. 28, p. 235-270, 2018.

ROJAS DONAT, L. Medieval Studies In Chile. Review Of Their Formation And Publications. Imago Temporis: Medium Aevum, n. 9, p. 47-65, 2015.

SÁNCHEZ-ALBORNOZ, C. La potestad real y los señoríos en Asturias, León y Castilla durante los siglos VIII al XIII. Revista de Archivos Bibliotecas y Museos, n. 21, p. 263-293, 1914.

SÁNCHEZ-ALBORNOZ, C. La curia regia portuguesa: Siglos XII-XIII. Madrid: Junta Para la Ampliación de Estudios-Centro de Estudios Históricos, 1920.

SÁNCHEZ-ALBORNOZ, C. Reseña. In:BARRAU-DIHIGO, Louis. Recherches sur I'histoire politique du royaume asturien (718-910). Anuario de historia del derecho español, n. 2, p. 531-537, 1925.

SÁNCHEZ-ALBORNOZ, C. Discursos leídos ante la Real Academia de la Historia en la recepción de Don Claudio Sánchez-Albornoz y Menduiña el 28 de febrero de 1926. Estampas de la vida en León durante el siglo X. Discurso de contestación de Ramón Menéndez Pidal. Madrid: Tipografía de la Revista de Archivos, 1926.

SÁNCHEZ-ALBORNOZ, C. Muchas páginas más sobre las behetrías. Frente a la última teoría de Mayer sobre ellas. Anuario de Historia del Derecho Español, n. 4, p. 5-157, 1927.

SÁNCHEZ-ALBORNOZ, C. La creación del Instituto de Estudios Medievales y los Monumenta Hispaniae Historica. Anuario de Historia del Derecho Español, n. 9, p. 504-508, 1932.

SÁNCHEZ-ALBORNOZ, C. La Semana de Historia del Derecho español (Madrid, Salamanca). Anuario de Historia del Derecho Español, n. 9, p. 487-493, 1932.

SÁNCHEZ-ALBORNOZ, C. En torno a los orígenes del feudalismo. Mendoza: Universidad Nacional de Cuyo, 1942.

SÁNCHEZ-ALBORNOZ, C. Otra vez Guadalete y Covadonga. Cuadernos de Historia de España, n. 1 y 2, p. $11-114,1944$.

SÁNCHEZ-ALBORNOZ, C. Serie de documentos inéditos del reino de Asturias. Cuadernos de Historia de España, n. 1-2, p. 298-351, 1944.

SÁNCHEZ-ALBORNOZ, C. El Ajbar Maymua. Cuestiones historiográficas que suscita. Buenos Aires: Universidad de Buenos Aires, Instituto de Historia de la Cultura Española, Medioeval y Moderna, 1944.

SÁNCHEZ-ALBORNOZ, C. Varia. Instituto de Estudios Históricos Doutor Antonio de Vasconcelos. Cuadernos de Historia de España, 1-2, p. 416-417, 1944.

SÁNCHEZ-ALBORNOZ, C. Dónde y cuándo murió don Rodrigo, último rey de los godos. Cuadernos de Historia de España, n. 3, p. 5-105, 1945.

SÁNCHEZ-ALBORNOZ, C. Documentos de Samos de los Reyes de Asturias. Cuadernos de Historia de España, n. 4, p. 147-160, 1946.

SÁNCHEZ-ALBORNOZ, C. En apoyo de dos viejas tesis. Cuadernos de Historia de España, n. 5, p. 129-139,1946.

SÁNCHEZ-ALBORNOZ, C. El Senatus Visigodo. Don Rodrigo, rey legítimo de España. Cuadernos de Historia de España, n. 6, p. 5-99, 1946.

SÁNCHEZ-ALBORNOZ, C. La España musulmana según los autores islamitas y cristianos medievales. Buenos Aires: El Ateneo, 1946.

SÁNCHEZ-ALBORNOZ, C. Orígenes de la Nación española. Estudios críticos sobre la historia del reino de Asturias. Oviedo: Instituto de Estudios Asturianos, 1972-1975.

SÁNCHEZ-ALBORNOZ, C. Historia y libertad: ensayos sobre historiología. Madrid: Júcar, 1974.

TOMÁS Y VALIENTE, F. Eduardo de Hinojosa y la historia del Derecho en España. Anuario de Historia del Derecho Español, n. 63-64, p. 1065-1088, 1993-1994.

WECKMANN, L. La sociedad feudal: esencias y supervivencias. México: Jus, 1944. 


\section{Notas}

${ }^{1}$ El presente artículo forma parte del proyecto “Claudio Sánchez-Albornoz (1893-1984): una biografía intelectual”, investigación apoyada por el programa PASPA-DGAPA, UNAM. Agradezco a los profesores Ariel Guiance, Mariano Otero y Leonardo Funes, así como a sus respectivos centros de investigación, todas las facilidades brindadas en Buenos Aires para poder llevar a cabo esta investigación.

${ }^{2}$ A Saavedra le acusará en otro artículo de cometer numerosos "pecados contra la crítica histórica y científica interpretación de los textos" (SÁNCHEZ-ALBORNOZ,1945, p.13) y calificaría su tesis de "desgraciada" (p. 17), Ilamándole con ironía mal disimulada "ingeniero-historiador" (p. 17) o “ingeniero arabista” (p. 31).

${ }^{3}$ Expediente de Claudio Sánchez-Albornoz y Menduiña. Junta de Ampliación de Estudios. Residencia de Estudiantes. Madrid. Fs. $1^{\text {a }}$.7d.

4 “Expediente de méritos y servicios de Sánchez-Albornoz y Menduiña, Claudio. 1919-1920". Universidad de Valladolid. Facultad de Filosofía y Letras. Archivo Histórico. Caja AHO. Legajo 2535. Expediente $N^{\circ} 38$.

${ }^{5}$ El trabajo sería publicado cinco décadas después bajo el título Orígenes de la Nación española (SÁNCHEZ-ALBORNOZ, 1977-1975).

${ }^{6}$ Hoy sabemos que el archivo fotográfico se salvó de los avatares de la guerra y se conserva en el Archivo del Centro de Estudios en Humanidades del Consejo Superior de Investigaciones Científicas de Madrid.

${ }^{7}$ Los artículosperiodísticos serían publicados conjuntamente en 1974 bajo el título Ensayos sobre historilogía (SÁNCHEZ-ALBORNOZ, 1974)

${ }^{8}$ De Simonet escribe, por ejemplo: “No logró éste, como no lo ha logrado jamás historiador alguno, librarse de sus apriorismos o convicciones filosóficas, religiosas o políticas al escribir su obra; pero procuró poner freno a la imaginación y tratar a las fuentes con el respeto que se merecen" (SÁNCHEZ-ALBORNOZ, 1944a, p. 21).

9 “[...] No me atrevo - asevera - a llegar a conclusiones definitivas, porque no dispongo en Buenos Aires de los cronistas que trazaron la historia de los siglos XI y XII de Al-Andalus, ni de los geógrafos que nos ha legado descripciones de la península hispánica en tal época". (SÁNCHEZ-ALBORNOZ, 1944a, p. 48). Reproduzco, a modo de ejemplo, una nota en la que enumera los textos que echa en falta en la capital argentina: “No dispongo, por ejemplo, de las ediciones: A) De Antuña de Ibn Hayyan: Al-Muqtabis. Tome troisième. Chronique du règne du Calife Umayade Abd Allah à Cordoue. Texte árabe publié pour la première fois d'après le manuscripte de la Bodle-ïanne, avec une introduction par... (Textes arabes relatifs à l'histoire de l'Occident musulmane III, Paris, 1838). B) De Lévi-Provençal: Ibn Idari al-Marrakixi, III. Histoire de l'Espagne musulmane au Xlème siècle. Texte árabe publié pour la première fois d'après un manuscript de Fés. Textes et indices. (Textes arabes relatifs à l'histoire de l'Occident musulman, I, Paris, 1930). C) De las obras geográficas de Ibn Jurdad-bah, Al-Ya qubi, Al-Istajri, Ibn Hauqal, Al-Masmudi [...]" (SÁNCHEZ-ALBORNOZ, 1944a, p. 48, nota 157). Con el tiempo, el madrileño se iría haciendo de estas ediciones, en particular de la obra de Lévi-Provençal, que se resguarda en la biblioteca personal de Sánchez-Albornoz hoy custodiada en el Centro Argentino de Estudios Históricos Claudio Sánchez-Albornoz.

${ }^{10}$ La denuncia del "hipercriticismo feroz" de Louis Barrau-Dihigo, quien "rechazó la autenticidad de la mayor parte de los diplomas reales” (SÁNCHEZ-ALBORNOZ, 1944, p. 299) fue constante y el abulense llegaría a decir de quien fuera director de la Sorbona que su "argumentación [...] es en apariencia muy rigurosa, pero examinada con cuidado carece de valor [...]" (SÁNCHEZ-ALBORNOZ, 1946a, p. 149). Sánchez-Albornoz conocía muy bien las Recherches sur l'histoire politique du royaume asturien (718-910) de Barrau-Dihigo (BARRAU-DIHIGO,1921) a las que en su día había dedicado una exhaustiva reseña (SÁNCHEZ-ALBORNOZ, 1925).

${ }^{11}$ Entre las críticas que hace a Barrau-Dihigo señala que éste tenía “[...] el deber de estudiar la autenticidad de los diplomas atribuidos al príncipe cuya historia escribía; no acertó siempre a leer las fechas de los que dio a la estampa, y no dispuso, para la edición de los originales de los mismos, sino de copias modernas. Y Millares ha publicado en su Paleografía Española, 2. ed., p. 193, una donación de Taiellus a la iglesia de S. Esteban “iusta flumen Narcegia”, fechada en 889, que yo fotocopié en el Archivo Catedral de Oviedo y que utilicé en mis clases de Madrid” (SÁNCHEZ-ALBORNOZ, 1944c, p. 300). Y añade, ufano: "Y descubrí el texto inédito del segundo en el Archivo Catedral Ovetense, tras domar al feroz y melifluo cancerbero del mismo. Poseo aquí fotografías de los dos y los reproduciré conforme en ellas los leo. Y añadiré a esas escrituras privadas de interés especial, cuyas copias he salvado pero de muchos de cuyos textos no tengo en Buenos Aires reproducciones fotográficas" (SÁNCHEZ-ALBORNOZ, 1944c, p. 301).

${ }^{12}$ Lo cuenta con soltura en el artículo periodístico “Las fuentes históricas”, La Prensa, Buenos Aires, 17 de mayo de 1943. Reproducido en SÁNCHEZ-ALBORNOZ (1974, p. 41-50). 